\title{
Immune response to measles vaccine after mass vaccination in Urmia, Islamic Republic of Iran
}

Z. Yekta, ${ }^{1}$ R. Pourali, ${ }^{1}$ M.R. Taravati, ${ }^{2}$ S. Shahabi, ${ }^{2}$ S. Salary, ${ }^{1}$ F. Khalily ${ }^{2}$ and A. Farzin ${ }^{3}$

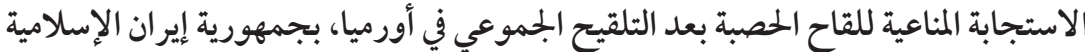

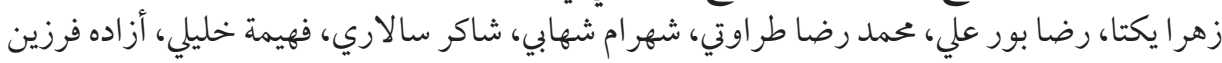

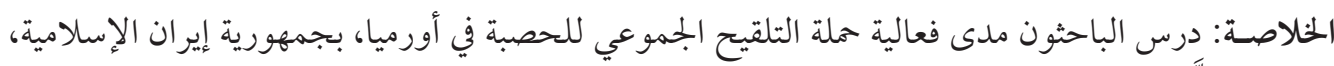

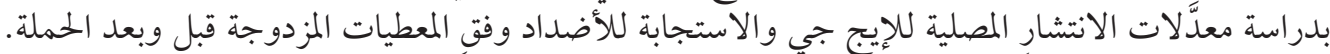

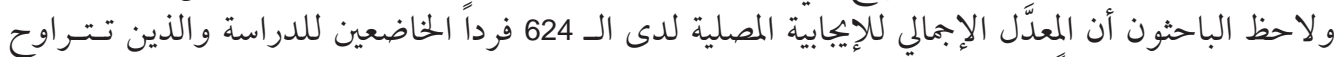

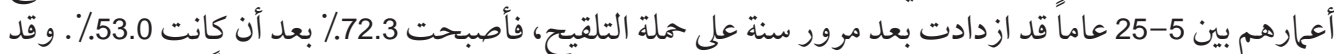

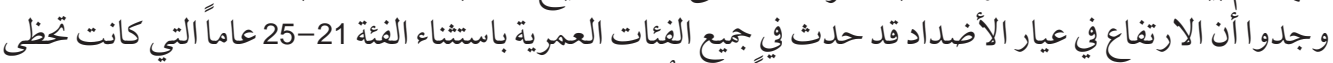

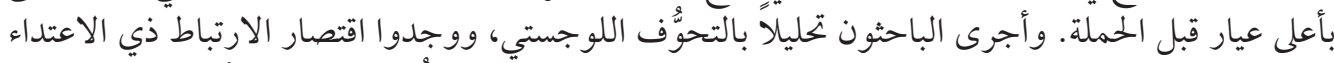

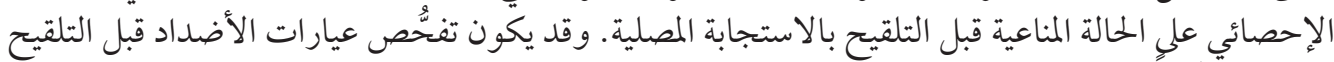

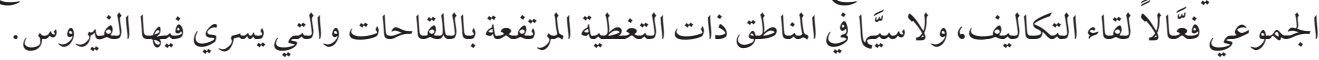

ABSTRACT We investigated the effectiveness of the mass measles vaccination campaign in Urmia, Islamic Republic of Iran, by examining the measles IgG seroprevalence and antibody response from paired data before and after the campaign. The overall seropositive rate of 624 subjects aged 5-25 years increased 1 year after the mass vaccination (from 53.0\% to $72.3 \%$ ). A rise in antibody titre occurred in all age groups except the 21-25 years group, which had the highest titre before mass vaccination. On logistic regression analysis, only immune status prior to vaccination was significantly associated with the seroresponse. It may be cost-effective to check antibody titres before mass vaccinations, especially in high vaccine coverage regions with circulating wild virus.

Réponse immunitaire au vaccin antirougeoleux après une vaccination de masse à Orumieh (République islamique d'Iran)

RÉSUMÉ Nous avons étudié l'efficacité de la campagne de vaccination antirougeoleuse de masse à Orumieh (République islamique d'Iran) en examinant la séroprévalence des IgG anti-rougeole et la réponse en anticorps à partir de données appariées avant et après la campagne. Le taux global de séropositivité de 624 sujets âgés de 5 à 25 ans augmentait un an après la vaccination de masse (il passait de 53,0 à 72,3\%). Une augmentation du titre d'anticorps était observée dans tous les groupes d'âges, à l'exception des 21-25 ans, qui avaient le titre le plus élevé avant la vaccination de masse. Selon l'analyse de régression logistique, seul le statut immunitaire avant la vaccination était significativement associé à la réponse sérologique. II peut s'avérer économiquement efficace de vérifier les titres d'anticorps avant les vaccinations de masse, notamment dans les régions où la couverture vaccinale est élevée et où le virus sauvage circule.

${ }^{1}$ Department of Community Medicine; ${ }^{2}$ Department of Immunology, Faculty of Medicine, Urmia University of Medical Sciences, Urmia, Islamic Republic of Iran (Correspondence to Z. Yekta: yekta42@yahoo.com). ${ }^{3}$ University of Cincinnati College of Medicine, Cincinnati Children's Hospital Medical Center, Cincinnati, Ohio, United States of America.

Received: 10/10/06; accepted: 17/12/06

المجلة الصحية لشرق المتوسط، منظمة الصحة العالمية، المجلد الخامس عشر، العلد ب، 9 ×. ب 


\section{Introduction}

Measles is an important vaccine-preventable childhood disease which causes considerable mortality and morbidity in developing countries [1]. It remains a significant public health problem, killing an estimated 1 million people worldwide each year [2].

Although measles vaccination is highly effective in children in the developing world when performed in carefully monitored settings $[3,4]$, vaccination programmes have not been uniformly successful [5]. Most cases of measles in vaccinated persons occur in the subset of individuals who did not undergo serological conversion after vaccination. This is known as primary vaccine failure [6]. The frequency of primary vaccine failure is variable and has been shown to be function of age at the time of vaccination, the number of doses, the immunogenicity of the strain of the virus used to manufacture the vaccine, improper handling and geographic region [7-11]. Development of protective immunity after vaccination also depends on several other factors. Familial aggregation was observed in poor responders to measles vaccine, suggesting a genetic basis for variation in the antibody response to vaccine $[12,13]$. Maternal antibody status, intercurrent infection and nutritional status have also been mentioned in several studies [14-16].

Measles vaccination was introduced to all parts of the Islamic Republic of Iran in 1970 and in recent decades it has been delivered as 2 routine doses of vaccine (at ages 9 and 15 months). The continuing occurrence of measles in older children, and the experience of other countries, led to the decision to administer a compulsory single dose of measles, mumps and rubella (MMR) vaccine to the whole population aged 5-25 years in August 2003 regardless of their vaccination status. The overall coverage of MMR vaccine after the mass campaign as reported by the Iranian Ministry of Health and Medical Education was estimated to be $97 \%$. Very high vaccination coverage of more than $95 \%$ may be needed to interrupt transmission of the highly contagious measles virus [15-17].

This study was undertaken to investigate the effectiveness of the campaign in Urmia city and the surrounding area, by examining the measles $\operatorname{IgG}$ seroprevalence and antibody response in paired data before and after the mass measles vaccination campaign. It was expected that the data obtained would help to assess the feasibility of measles elimination in the country.

\section{Methods}

The measles mass vaccination campaign in the Islamic Republic of Iran was conducted in the 5-25 year age group from 1 December to 31 December 2003. During the campaign, a total of 387317 people in Urmia received the MMR vaccine provided by the Iranian Department of Health. The vaccination was performed with $0.5 \mathrm{~mL}$ of vaccine (Serum Institute of India, Pune, India).

\section{Study sites and population}

Our study was undertaken in Urmia from 25 September to 25 November 2003 (before the mass campaign) and from 25 September to 25 November 2004 (after the campaign). Sampling was performed in 2 stages; initially we selected 8 health care centres from a total of 18 such centres in the city by cluster sampling (based on data from the local deputy for health) and 00 subjects aged 5-25 years meeting our criteria were selected by simple random sampling after stratifying for age and sex at each health 
care centre. Health care centres hold data about the characteristics of residents such as age and sex.

Just before the vaccination campaign, a sample of $5 \mathrm{~mL}$ blood was drawn from the 800 selected residents. Blood was centrifuged and the plasma was removed and frozen at $-76{ }^{\circ} \mathrm{C}$ until assay. Individuals with a previous history of measles and those with any immune-compromising conditions were excluded. All participants were interviewed and information about previous vaccination was validated from health centre records. Those who reported having at least 1 dose of measles vaccination during childhood (9 or 15 months of age) were included. Patients who did not have their vaccination status recorded on the official vaccine card were excluded.

At 12 months after the mass vaccination, blood samples were obtained from the same subjects. A total of 176 (21.8\%) people were unavailable for follow-up; therefore 625 subjects participated in both the before and after studies. Although most of the loss occurred in the 15-25 year age group, it was not statistically different from the attrition in the other age groups.

The study was approved by the ethics committees of both Urmia University of Medical Sciences and the local deputy for health.

\section{Serology}

The antimeasles antibody levels were measured with an enzyme-linked immunosorbent assay (ELISA) of IgG antibodies using a commercial kit (Immuno-Biological Laboratories Inc., Hamburg, Germany). The sensitivity and specificity of the measles IgG ELISA test reported by the manufacturer were both $>95 \%$. The cut-off titres were set as follows: seronegative $<8 \mathrm{IU} / \mathrm{mL}$, borderline $8-12 \mathrm{IU} / \mathrm{mL}$ and seropositive $>$ $12 \mathrm{IU} / \mathrm{mL}$.

\section{Statistical analysis}

Data on age (categorized into 4 groups: 5-10, 11-15, 16-20, 21-25 years), sex, history of measles vaccination status (1 or 2 times) were obtained from all the subjects in the sample. Measles IgG seroprevalence and the mean [standard deviation (SD)] antibody titres were compared before and after vaccination. Immune response was considered as an increase in the mean antibody titre after vaccination.

The relationship was assessed between vaccination antibody response (changes in mean of antibody before and after mass vaccination) (dependent variable) and age group, sex, immunity status and vaccination status (ndependent variables). Data were analysed by SPSS, version 11. Chisquared, Kruskall-Wallis, Wilcoxon and Mann-Whitney U tests were performed as appropriate in 2-tailed analyses. Logistic regression analysis was also used to examine the relationship between the vaccination antibody response (rising antibody after mass vaccination) (dichotomized dependent variable) with sex, age, history of vaccination ( 1 or 2 previous doses of measles vaccine) and antibody status before vaccination, while controlling for potential confounding variables [marital status, ethnicity (Turkish, Persian, Kurdish), education level]. All variables were entered in the model to obtain the odds ratio (OR) and 95\% confidence interval (CI) adjusted for the significant predictors of the seroresponse. $P$-value $<$ 0.05 was considered significant.

\section{Results}

A total of 625 subjects were tested by comparing the mean of level of antimeasles antibodies and the prevalence of antibody seropositivity before and after vaccination.

Before vaccination, 193/625 (30.9\%) of subjects had negative antibody titres $(<8$ IU/ 
$\mathrm{mL})$ and $101(16.3 \%)$ had borderline titres. After vaccination only $86(13.8 \%)$ remained negative and 87 (13.9\%) had borderline titres. Although the overall seropositivity rate increased after mass vaccination from $331 / 625(53.0 \%)$ before the mass campaign to $452 / 625(72.3 \%)$ after $(P<0.05)$, the mean antibody titre before mass vaccination showed no significant difference compared with the titre after the mass campaign: 47.1 (SD 3.5) IU/mL versus 46.4 (SD 2.4) IU/ $\mathrm{mL}$.

Table 1 provides comparisons of mean antibody titres and seropositivity before and after the mass vaccination campaign by subjects' characteristics. An increase in the prevalence of seropositivity was observed in all age groups and the increment was slightly greater in the 16-20 years group. A rise in the mean antibody titre occurred in participants aged $<20$ years after the mass vaccination. However, the mean antibody titre decreased significantly in the 21-25- year-olds, who had the highest antibody titres before mass vaccination, so a negative response was observed in this age group $(P$ $<0.05$ ) (Figure 1).

The response to vaccination based on subjects' immunity level showed a considerable increase in antibody titre in seronegative and borderline subjects, but seropositive individuals showed a significantly decrease in antibody titre after vaccination $(P<0.05)$. In other words, among the seropositive subjects the mean antibody titre reached a lower level after the mass vaccination compared to before $(P<0.05)$ (Figure 2$)$.

We also compared the response to vaccination based on antibody titres before vaccination. This showed that the increase in antibody titre was inversely proportional to the prevaccination titre; having a titre $>100$ $\mathrm{IU} / \mathrm{mL}$ prior to vaccination was associated with a negative response after vaccination.

Of the 625 participants, $429(68.64 \%)$ had a history of vaccination administered 2

Table 1 Measles seropositive rates before and after the mass vaccination campaign and proportion of vaccination responders by subjects' characteristics

\begin{tabular}{|c|c|c|c|c|c|c|c|c|c|}
\hline \multirow[t]{3}{*}{ Variable } & \multirow[t]{3}{*}{$\begin{array}{l}\text { Total } \\
\text { no. }\end{array}$} & \multicolumn{3}{|c|}{$\begin{array}{l}\text { Before mass vaccination } \\
\qquad(n=625)\end{array}$} & \multicolumn{3}{|c|}{$\begin{array}{c}\text { After mass vaccination } \\
\qquad(n=625)\end{array}$} & \multicolumn{2}{|c|}{$\begin{array}{l}\text { Vaccination } \\
\text { responders }\end{array}$} \\
\hline & & \multicolumn{2}{|c|}{ Seropositive } & \multirow{2}{*}{$\begin{array}{c}\text { Mean (SD) } \\
\text { IgG titre } \\
(I U / m L)\end{array}$} & \multicolumn{2}{|c|}{ Seropositive } & \multirow{2}{*}{$\begin{array}{c}\text { Mean (SD) } \\
\text { IgG titre } \\
(I U / m L)\end{array}$} & \multirow[b]{2}{*}{ No. } & \multirow[b]{2}{*}{$\%$} \\
\hline & & No. & $\%$ & & No. & $\%$ & & & \\
\hline \multicolumn{10}{|c|}{$\overline{\text { Age (years) }}$} \\
\hline $5-10$ & 187 & 87 & 46.5 & 35.7 (12.2) & 127 & 67.9 & $38.8(14.2)$ & 135 & 72.2 \\
\hline $11-15$ & 170 & 80 & 47.1 & $28.5(7.4)$ & 110 & 64.7 & $29.4(9.7)$ & 130 & 76.5 \\
\hline $16-20$ & 137 & 66 & 48.2 & $28.7(9.3)$ & 101 & 73.7 & $36.3(11.4)$ & 105 & 76.6 \\
\hline $21-25$ & 131 & 98 & 74.8 & $106.8(21.2)$ & 114 & 87.0 & $89.8(12.1)$ & 72 & 55.0 \\
\hline \multicolumn{10}{|c|}{$\begin{array}{l}\text { Prior measles } \\
\text { vaccination }\end{array}$} \\
\hline 1 dose & 196 & 136 & 69.4 & $80.1(14.8)$ & 166 & 84.7 & $69.9(17.2)$ & 130 & 66.3 \\
\hline 2 doses & 429 & 195 & 45.5 & $32.0(8.2)$ & 286 & 66.7 & $35.6(12.7)$ & 312 & 72.7 \\
\hline \multicolumn{10}{|l|}{ Sex } \\
\hline Male & 287 & 157 & 54.7 & $50.1(10.2)$ & 207 & 72.1 & $45.2(12.6)$ & 196 & 68.3 \\
\hline Female & 338 & 174 & 51.5 & $44.6(7.7)$ & 245 & 72.5 & $47.4(10.5)$ & 246 & 72.8 \\
\hline
\end{tabular}

${ }^{a}$ Antibody titre $>12 \mathrm{IU} / \mathrm{mL} ;{ }^{b}$ Higher antibody titre after mass vaccination.

$\mathrm{n}=$ total number of subjects; $S D=$ standard deviation.

المجلة الصحية لشرق المتوسط، منظمة الصحة العالمية، المجلد الخنامس عشر، العدد ب، 9 +. 


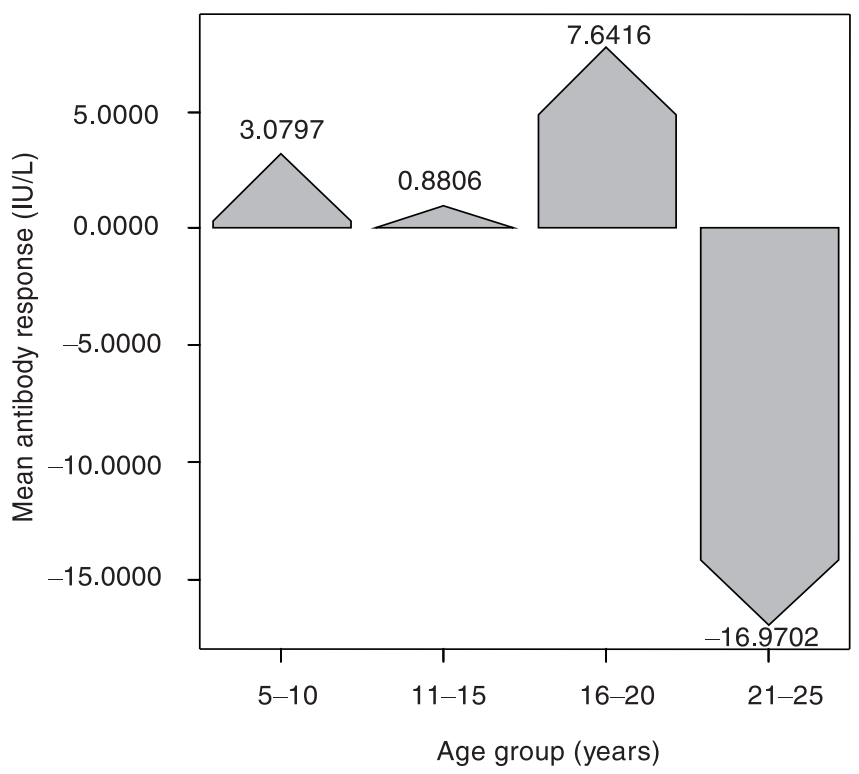

Figure 1 Mean antibody response before and after the mass vaccination campaign by age group

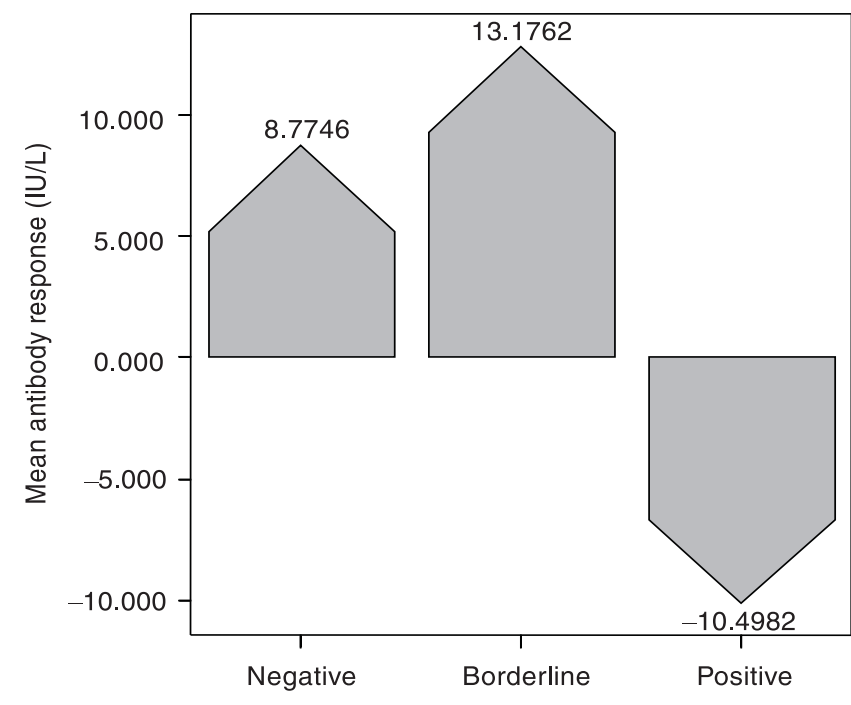

Antibody titre before mass vaccination

Figure 2 Mean antibody response before and after the mass vaccination campaign by vaccination immunity status before campaign (seronegative $<8 \mathrm{IU} / \mathrm{mL}$, borderline 8-12 IU/mL, seropositive $>12(\mathrm{I} / \mathrm{mL})$

المجلة الصحية لشرق المتوسط، منظمة الصحة العالمية، المجلد الخامس عشر، العدد ؟، 9 +. ب 
times during childhood (9 and 15 months). The proportion of vaccination responders was slightly higher among those who had had 2 prior doses of vaccine than only 1 dose (Table 1). The mean antibody responses based on vaccination history in different age groups are shown in Table 2. The results show that there was a significant difference in antibody response according to vaccination history only in the $16-20$ year age group.

The mean level of antimeasles antibodies was slightly lower after vaccination in males than females (Table 1) (mean titre $45.2 \mathrm{IU} / \mathrm{L}$ versus $47.4 \mathrm{IU} / \mathrm{L}$ ). However, there was a significant difference in the mean antibody response according to sex [-4.9 (SD 3.2) IU/L for males versus 2.8 (SD 2.6) IU/L for females] $(P<0.05)$.

We used multiple logistic regression analysis to estimate the association between antibody status before mass vaccination as categorical independent variables (negative, borderline, positive) and the antibody response after the mass vaccination campaign, while controlling for the effect of potentially confounding variables such as age group, sex and vaccination history during childhood. A significant relationship was seen between previous antibody level and response to vaccination. The reference category for the model was the seronegative group. The ORs for borderline and positive participants before vaccination were 0.38 (95\% CI: $0.15-0.81)$ and 0.16 (95\% CI: $0.1-0.67)(P<0.05)$ respectively.

\section{Discussion}

Vaccine failure is one of the factors responsible for the high incidence of measles after the introduction of measles vaccine into the Expanded Programme of Immunization (EPI) [18]. Despite the success of the current vaccine in controlling the disease, the importance of vaccine failure has become increasingly apparent [19]. Mass catch-up measles vaccination campaigns are recommended by the World Health Organization (WHO) as one of the main strategies to control or eliminate measles [20].

Despite the $97 \%$ vaccination coverage reported by the Ministry of Health after the

\begin{tabular}{|c|c|c|c|c|c|}
\hline $\begin{array}{l}\text { Age group } \\
\text { (years) }\end{array}$ & $\begin{array}{c}\text { IgG titre } \\
\text { vaccination } \\
\text { history }\end{array}$ & $\begin{array}{c}\text { Before mass } \\
\text { vaccination } \\
(n=625) \\
\text { Mean }(S D) \\
\text { IgG titre } \\
(I U / m L) \\
\end{array}$ & $\begin{array}{c}\text { After mass } \\
\text { vaccination } \\
(n=625) \\
\text { Mean (SD) } \\
\text { IgG titre } \\
(I U / m L) \\
\end{array}$ & $\begin{array}{c}\text { Mean } \\
\text { antibody } \\
\text { response } \\
(I U / m L)\end{array}$ & P-value \\
\hline \multirow[t]{2}{*}{$5-10$} & 1 dose & $47.1(20.5)$ & $51.5(16.5)$ & 4.4 & 0.97 \\
\hline & 2 doses & $35.3(4.7)$ & 38.3 (3.6) & 3.0 & \\
\hline \multirow[t]{2}{*}{$11-15$} & 1 dose & $41.7(12.4)$ & $41.3(22.7)$ & -0.4 & 0.87 \\
\hline & 2 doses & $27.0(2.9)$ & $28.0(4.7)$ & 1.0 & \\
\hline \multirow[t]{2}{*}{$16-20$} & 1 dose & 36.1 (8.5) & $35.4(4.8)$ & -0.6 & 0.041 \\
\hline & 2 doses & 23.5 (4.2) & $37.0(4.9)$ & 13.5 & \\
\hline \multirow[t]{2}{*}{$21-25$} & 1 dose & $110.3(13.4)$ & $92.9(8.5)$ & -17.4 & $<0.001$ \\
\hline & 2 doses & $83.4(30.6)$ & 69.5 (19.5) & -13.9 & \\
\hline
\end{tabular}

$n=$ total number of subjects; $S D=$ standard deviation. 
mass vaccination in Urmia, the seropositivity rate only reached about $75 \%$, far below the herd immunity level of $95 \%$ needed to halt transmission [21], which means that almost $25 \%$ of the target group had no immunity. Kuroiwa et al. in Laos reported that the seroconversion rate of measles antibody was as low as $74 \%$ even though the mass campaign was more intensive than a routine immunization service. This finding reflects the difficulty of increasing the immunity of children at the community level by mass measles vaccination campaigns [22]. This low seroconversion rate was consistent with the vaccine efficacy through routine immunization $(68 \%)$, which was estimated in Kuroiwa's previous study [23]. This problem, which has also been highlighted by our study, is confirmed by the low seropositive rate among young people with a vaccine history before the campaign (53\%).

Kuroiwa et al. also revealed that the campaign seemed to be more useful in weak EPI activity areas, where the reduction of measles cases is urgently needed [22].

Several other authors estimated that the prevalence of susceptibility to either clinical or subclinical reinfection in vaccinated populations was 19\%-31\% [24]. The degree of population immunity to achieve measles elimination in Asia has not been established at present. Although an ideal susceptibility level could be very different for different countries, as a whole the serological profile against measles in Urmia was well below the WHO target levels for Europe [25].

Although mass vaccination raised the measles seropositive rate (from 53\% to $73 \%$ ) in Urmia, we cannot, however, expect the same positive impact on measles elimination. This means that some individuals in our study are "poor responders" to vaccination, and will be at risk of subclinical infection relatively soon after immunization [26].
Many observations have suggested that some factors may limit the capacity of children in the developing world to mount a response to vaccination. These include factors in the child, such as nutritional status, specific micronutrient status [21] and chronic or inter-current infections [5,21], as well as factors in the system, such as poor maintenance of the cold-chain supply [27] or purchase of suboptimal products [28]. Moreover, recent findings show that genetic factors play a role in determining vaccination success in different geographic regions $[29,30]$.

The findings of serological analysis in the present study show a higher antibody response among females. This is in agreement with the general concept that measles antibodies in women are marginally higher than that in men $[1,31]$.

Our results show that the pre-immunization antibody level was inversely correlated with the response to vaccination. This finding is in agreement with other studies showing that high measles antibody titres interfere with the mean antibody response, and the greatest increase occurred in those with the lowest pre-immunization titres [25,32-35]. Therefore antibody response titres were significantly inversely correlated with antibody status before mass vaccination, i.e. subjects with high antibody status showed a weak response [26,36-39].

The vaccination response was slightly higher in those who had received 2 previous doses of measles vaccine compared with those who had only 1 dose, but this difference was not significant. When this was analysed for different age groups, the 16-20-year-old group had a significantly stronger response among participants who had had 2 previous doses of vaccine compared with those receiving only 1 dose. However, in the other age groups there was no significant difference in this parameter. The may be due to 
the existence of higher pre-immunization levels of measles antibody in the serum of participants who received 2 previous doses than that of participants who had 1 previous dose. The cause of a higher pre-immunization antibody level in participants with 1 dose may be a lower immunity against measles virus in these persons compared to participants with 2 doses, and consequently a higher rate of subclinical infection by wild measles virus in participants with 1 prior dose of vaccine.

The age-specific vaccination response showed a considerable decrease in the mean antibody titre after vaccination in the $>$ 20 years age group, and the proportion of subjects with a higher mean antibody level after vaccination was higher in those aged 5-20 years old. However, the lack of an increasing antibody titre after vaccination at age $>20$ years can be related to the inhibitory effects of the high pre-immunization antibody level in this age group, although this cannot explain the decreased antibody titre after immunization by itself. The decrease in antibody titre may be related to a balance between the humoral and cellular response to measles virus. Having a higher level of antibody before reimmunization might produce a lower antibody response after revaccination. Such an effect has been proposed for maternal antimeasles antibodies [35].

Based on the vaccination response in age groups 16-20 and 20-25 years old, it seems to be cost-effective to check antibody titres before mass vaccination, especially in high vaccine coverage regions with circulating wild virus. It is clear that a more detailed understanding is needed of the immune response to measles vaccination in young people in developing countries and the factors that limit or modify this response if we are to succeed in the drive towards eradicating measles [21].

In summary, with vaccine-maintained herd immunity, it may be possible to eradicate certain infectious disease. However, large-scale vaccination programmes will shift the age distribution of cases, which might have serious consequences [40]. We suggest that periodical serological studies are needed to determine the seropositivity level at different ages.

\section{Acknowledgements}

Financial support was provided by Urmia University of Medical Sciences and the Health Deputy. We thank Mahnaz Kafily and Ebrahim Tarive for their technical assistance.

\section{References}

1. Lyamuya EF et al. Serum levels of measles IgG antibody activity in children under 5 years in Dar-es-Salaam, Tanzania. Annals of tropical paediatrics, 1999, 19(2):175-83.

2. Ovsyannikova IG et al. Associations between human leukocyte antigen (HLA) alleles and very high levels of measles antibody following vaccination. Vaccine, 2004, 22(15-16):1914-20.

3. Henderson RH et al. Global control of vaccine-preventable diseases: how progress can be evaluated. Reviews of infectious diseases, 1989, 11(Suppl. 3):S649-54.

4. Cutts FT et al. Successes and failures in measles control. Journal of infectious diseases, 1994, 170(Suppl. 1):S32-41.

5. Bautista-Lopez NL et al. Immune response to measles vaccine in Peruvian children. Bulletin of the World Health Organization, 2001, 79(11):1038-46.

6. Hayden GF. Measles vaccine failure. A survey of causes and means of prevention.

المجلة الصحية لشرق المتو سط، منظمة الصحة العالمية، المجلد الخامس عشر، العدد ب، 9 +. 
Clinical pediatrics, 1979, 18(3):155-6, 161-3, 167

7. Black FL et al. Inadequate immunity to measles in children vaccinated at an early age: effect of revaccination. Bulletin of the World Health Organization, 1984, 62(2):315-9.

8. Centers for Disease Control and Prevention. Update: changes in notifiable disease surveillance data-United States, 1992-1993. Morbidity and mortality weekly report, 1993, 42(42):824-36.

9. Progress toward elimination of measles from the Americas. Morbidity and mortality weekly report, 1998, 47(10):189-93.

10. Mathias $R G$ et al. The role of secondary vaccine failures in measles outbreaks. American journal of public health, 1989, 79(4):475-8.

11. Paunio $M$ et al. Secondary measles vaccine failures identified by measurement of IgG avidity: high occurrence among teenagers vaccinated at a young age. Epidemiology and infection, 2000, 124(2):263-71

12. Poland GA et al. The genetic basis for variation in antibody response to vaccines. Current opinion in pediatrics, 1998, 10(2):208-15.

13. Janaszek W, Slusarczyk J. Immunity against measles in populations of women and infants in Poland. Vaccine, 2003, 21(21-22):2948-53.

14. Adu FD et al. Low seroconversion rates to measles vaccine among children in Nigeria. Bulletin of the World Health Organization, 1992, 70(4):457-60.

15. Albrecht $P$ et al. Persistence of maternal antibody in infants beyond 12 months: mechanism of measles vaccine failure. Journal of pediatrics, 1977, 91(5):715-8.

16. Expanded Programme on Immunization (EPI). Safety of high titer measles vaccines. Weekly epidemiological record, 1992, 67(48):357-61.
17. Garly ML et al. The challenge of improving the efficacy of measles vaccine. Acta tropica, 2003, 85(1):1-17.

18. Ariyasriwatana $\mathrm{C}$ et al. Antibody response after measles immunization. Journal of the Medical Association of Thailand, 2003, 86(Suppl. 3):S701-6.

19. Jacobson RM et al. The association of class I HLA alleles and antibody levels after a single dose of measles vaccine. Human immunology, 2003, 64(1):103-9.

20. Chuang SK et al. Mass measles immunization campaign: experience in the Hong Kong Special Administrative Region of China. Bulletin of the World Health Organization, 2002, 80(7):585-91.

21. Huang $C L$ et al. Humoral and cellular immune response after measles vaccination in Taiwan. Journal of microbiology, immunology, and infection, 2005 , 38(3):169-75.

22. Kuroiwa $C$ et al. Difficulties in measles elimination: prevalence of measles antibodies before and after mass vaccination campaign in Laos. Vaccine, 2003 , 21(5-6):479-84.

23. Kuroiwa $C$ et al. Measles epidemiology and outbreak investigation using $\lg \mathrm{M}$ test in Laos. Journal of epidemiology/ Japan Epidemiological Association, 2001, 11(6):255-62.

24. Muller CP. Measles elimination: old and new challenges? Vaccine, 2001, 19(1719):2258-61.

25. Kim SS et al. Sero-epidemiology of measles and mumps in Korea: impact of the catch-up campaign on measles immunity. Vaccine, 2004, 23(3):290-7.

26. Glass $\mathrm{K}$ et al. Waning immunity and subclinical measles infections in England. Vaccine, 2004, 22(29-30):4110-6.

27. Krugman RD et al. Impotency of live-virus vaccines as a result of improper handling in clinical practice. Journal of pediatrics, 1974, 85(4):512-4. 
28. Adu FD et al. Low seroconversion rates to measles vaccine among children in Nigeria. Bulletin of the World Health Organization, 1992, 70(4):457-60.

29. Tan PL et al. Twin studies of immunogenicity-determining the genetic contribution to vaccine failure. Vaccine, 2001, 19(17-19):2434-9.

30. Poland GA et al. Identification of an association between HLA class II alleles and low antibody levels after measles immunization. Vaccine, 2001, 20(3-4):430-8.

31. Gdalevich M et al. Measles antibody prevalence rates among young adults in Israel. American journal of infection control, 2002, 30(3):165-9.

32. Cutts FT, Badis F. Controle de la rougeole dans les pays en developpement [Measles control in developing countries]. Santé, 1994, 4(3):163-71.

33. Wong-Chew RM et al. Cellular and humoral immune responses to measles in immune adults re-immunized with measles vaccine. Journal of medical virology, 2003, 70(2):276-80.

34. Rager-Zisman B et al. The effect of measles-mumps-rubella (MMR) immunization on the immune responses of previously immunized primary school children. Vaccine, 2003, 21(19-20):2580-8.
35. Bertley FM et al. Measles vaccination in the presence of maternal antibodies primes for a balanced humoral and cellular response to revaccination. Vaccine, 2004, 23(4):444-9.

36. Crowe JE Jr. Influence of maternal antibodies on neonatal immunization against respiratory viruses. Clinical infectious diseases, 2001, 33(10):1720-7.

37. Wilkins $\mathrm{J}$ et al. Additional evidence against measles vaccine administration to infants less than 12 months of age: altered immune response following active/passive immunization. Journal of pediatrics, 1979 , 94(6):865-9.

38. Linnemann CC Jr et al. Measles immunity after revaccination: results in children vaccinated before 10 months of age. Pediatrics, 1982, 69(3):332-5.

39. Cohn ML et al. Measles vaccine failures: lack of sustained measles-specific immunoglobulin $\mathrm{G}$ responses in revaccinated adolescents and young adults. Pediatric infectious disease journal, 1994, 13(1):34-8.

40. Giesecke J. The epidemiology of vaccination. In: Giesecke J, ed. Modern infectious disease epidemiology. London, Hodder Arnold, 2002:226-40. 